\title{
Somatic mutations in myeloid cell leukemia-1 contribute to the pathogenesis of glioma by prolonging its half-life
}

\author{
XIUPENG LV*, GUANG TAN*, YIQUN YAO, LI LV, XIAOQIN DENG, \\ LEI DONG, SHUANG LI, LINLIN LI and YINGHUI XU
}

Department of Neurosurgery, The First Affiliated Hospital of Dalian Medical University, Dalian, Liaoning 116011, P.R. China

Received April 22, 2014; Accepted January 21, 2015

DOI: $10.3892 / \mathrm{mmr} .2015 .3493$

\begin{abstract}
The identification of mutated genes in glioblastoma multiforme (GBM) is an essential step towards improving current understanding of the molecular mechanism underlying the disease and establishing novel targets for diagnostic and therapeutic purposes. The present study used direct sequencing to screen 20 malignancy-associated genes, which have either been well described in the literature or observed multiple times in human cancer sequencing, in cancerous and normal control tissue samples from 20 patients with histologically confirmed GBM. The investigation identified five somatic non-synonymous coding mutations in four candidate genes, with two located in the proline, glutamic acid, serine, threonine-rich region of myeloid cell leukemia sequence 1 (Mcl)-1, (D155G and L174S). The sample pool was then expanded by sequencing Mcl-1 in a further 43 patients with GBM and another somatic mutation in the same region, $\mathrm{D} 155 \mathrm{H}$, was identified. The subsequent functional investigation confirmed that these somatic mutations affected the degradation of Mcl-1, and the growth of glioma cells transfected with mutant plasmids was significantly accelerated compared with cells overexpressing wild-type Mcl-1. The mutational profiling of GBM in the present study revealed for the first time, to the best of our knowledge, several mutations in Mcl-1, and identified this gene as a novel therapeutic target for the treatment of GBM.
\end{abstract}

\section{Introduction}

Glioma is a type of tumor, which grows from glial cells, a supportive cell in the brain, and is the most life-threatening

Correspondence to: Dr Yinghui Xu, Department of Neurosurgery, The First Affiliated Hospital of Dalian Medical University, 222 Zhongshan Road, Dalian, Liaoning 116011, P.R. China

E-mail: yinghuixu_glioma@163.com

${ }^{*}$ Contributed equally

Key words: glioblastoma multiforme, myeloid cell leukemia 1, somatic mutation, half-life type of brain tumor (1). Glioblastoma multiforme (GBM) is the most advanced and aggressive subtype of glioma, and patients with GBM have a median survival rate of $\sim 14$ months (2). As a complex medical condition, GBM is considered to be result from the interaction between multiple genetic and environmental factors (3). Currently, only a small number of low penetrance variants attributing to cancer risk have been identified using genome-wide association investigations (4), and the etiology remains to be elucidated. Previous efforts to comprehensively characterize the genomes of primary GBM have established that the disease is driven by numerous and diverse genetic events in individual patients $(5,6)$.

It is generally accepted that somatic mutations are important in the pathogenesis of cancer, and that cancer develops via the accumulation of somatic mutations in certain cancer-specific genes, including oncogenes and tumor suppressors, depending on the type of tumor (7). Previous studies have demonstrated that the frequency of somatic mutations in candidate cancer genes is significantly higher than expected, and that the combination of certain individual mutations may have a specific effect on the properties of the tumor (8-11). These mutations are considered to result from a combination of environmental and genetic factors (12). Following the determination of the human genome sequence, several investigations have been performed to determine somatic mutations in various types of cancer. The Sanger sequencing technique was used to directly sequence 13,023 genes, identifying 189 genes carrying excessive somatic mutations in human breast and colorectal cancer (10). A mismatch repair detection method was used to screen 22 cell lines and 93 matched tumor-control sample pairs, for somatic mutations in 30 cancer-associated genes A total of 152 somatic mutations were identified in breast and colorectal cancer (13), including genes, which are reported to be involved in the development of cancer, including Kirsten rat sarcoma virus oncogene and v-raf murine sarcoma viral oncogene homolog B (BRAF).

To further investigate the prevalence and distribution of somatic mutations in glioma, the present study aimed to examine 63 glioma tissues and their matched normal tissues for somatic mutations in 20 genes, which have been reported to as affirmatively or potentially associated with oncogenesis $(14,15)$. A total of six somatic mutations were identified, with three repeated somatic mutations observed exclusively in myeloid cell leukemia sequence 1 (Mcl-1). The effect of these somatic mutations were subsequently investigated. 


\section{Materials and methods}

Subjects and tumor samples. A total of 63 patients (42 male and 21 female) with histologically confirmed GBM were recruited at the Department of Neurosurgery, The Affiliated Hospital of Peking University (Beijing, China), where the patients received surgical resection. The median age of the patients was 55 years (range, 45-67 years) and none had received any preoperative treatment. All the tumor specimens were examined by two independent, experienced pathologists prior to establishing the final diagnosis. High-fidelity polymerase chain reaction (PCR) and direct sequencing were performed to screen the coding region of 20 genes (Mcl-1, Bcl-2, EGFR, KRAS, FGR, IKZF1, BTG1, TP53, PAX5, BRAF, BACH2, ARF, Bcl6, VEGF, HER2, $\beta$-catenin, c-myc, Rb, EZH2, E2F) for potential somatic mutations in 20 patients, and the gene of interest was further screened in the remaining 43 patients. The size of the tumor was determined by measuring the maximum tumor diameter presented on radiographic images, including computed tomography scans and magnetic resonance imaging. The tumor tissue samples were rapidly frozen immediately following surgical resection in liquid nitrogen and stored at $-80^{\circ} \mathrm{C}$ for future investigations. Peripheral blood samples $(5 \mathrm{ml})$ were acquired from all patients. Informed consent was obtained from the patient's families, and the present study was approved by the Review Board of the Hospital Ethics Committee at Dalian Medical University (Dalian, China).

DNA extraction and nucleotide sequencing analysis. Total genomic DNA was isolated from the GBM tumor tissue samples and peripheral blood using a DNA extraction kit (Invitrogen Life Technologies, Carlsbad, CA, USA). The isolated DNA was dissolved in sterilized Milli-Q water (EMD Millipore, Billerica, MA, USA) and quantified using a NanoDrop spectrophotometer (Thermo Fisher Scientific, Wilmington, DE, USA). Agarose electrophoresis (Sigma-Aldrich, St. Louis, MO, USA) was used to confirm the purity of the DNA. The chromosome segments comprising the coding region of each gene were amplified by PCR (primer set: forward 5'-GTATCGAGCTAGCGCTCCGCTATG-3' and reverse 5'-GTACTCTTCAGCGAGCTAGATAT-3'; Sangong Biotech, Shanghai, China), according to the following PCR cycling conditions: $95^{\circ} \mathrm{C}$ for $10 \mathrm{~min} ; 35$ cycles of $95^{\circ} \mathrm{C}$ for $30 \mathrm{sec}, 58^{\circ} \mathrm{C}$ for $30 \mathrm{sec}, 72^{\circ} \mathrm{C}$ for $1 \mathrm{~min}$, followed by $72^{\circ} \mathrm{C}$ for $10 \mathrm{~min}$. The PCR products were purified using an ExoSAP-IT purification kit (United States Biochemical Corp., Cleveland, $\mathrm{OH}, \mathrm{USA}$ ), prior to sequencing using an $\mathrm{ABI}$ sequencing system by PerkinElmer Applied Biosystems (Foster City, CA, USA). The sequences were subsequently aligned against the revised Cambridge sequence in the MITOMAP database (www.mitomap.org) using the MegAlin program from the DNAStar software package 12.1 (DNASTAR, Inc., Madison, WI, USA). The sequence alterations identified in the tumor tissue samples, but not in the matched peripheral blood samples, were recorded as somatic mutations. The screened somatic mutations were confirmed at least twice by additional independent PCR and resequencing.

Cell lines and cell culture. The U251 GBM cell line was cultured in RPMI-1640 medium (Invitrogen Life Technologies) containing 10\% fetal bovine serum (Sigma-Aldrich Canada Ltd., Oakville, Ontario, Canada), $100 \mathrm{U} / \mathrm{ml}$ penicillin and $100 \mathrm{mg} / \mathrm{ml}$ streptomycin (Invitrogen Life Technologies).

Apoptotic assay. Apoptosis was determined using an annexin V/fluorescein isothiocyanate (FITC) apoptosis detection kit (Keygen Biotech Co., Ltd., Nanjing, China), according to the manufacturer's instructions. Briefly, glioma cells $\left(2 \times 10^{8}\right.$ cells) cultured in $10 \mathrm{~cm}$ dishes were trypsinized (Invitrogen Life Technologies), washed with phosphate buffered saline (PBS) and subsequently stained with FITC-conjugated anti-annexin V antibody in the dark for $15 \mathrm{~min}$ at room temperature. The cells were then analyzed by flow cytometry (FACSCanto II; BD Biosciences, San Jose, CA, USA). All experiments were performed in triplicate.

Cell viability and proliferation assay. Cell proliferation was measured using a 3-(4,5-dimethylthiazol-2-yl)-2,5-diphenyltetrazolium bromide (MTT) assay. The cells were seeded into 96 -well plates at a density of 800 cells/well and were incubated at $75^{\circ} \mathrm{C}$ for 1,2 or 3 days. MTT $(20 \mu 1 ; 5 \mathrm{mg} / \mathrm{ml}$; Sigma-Aldrich) was added to each well and incubated for $4 \mathrm{~h}$ at room temperature. The supernatants were subsequently removed and $150 \mu$ ld dimethyl sulfoxide (Sigma-Aldrich) was added. The absorbance value of each well was measured at 490 nm (EnSight ${ }^{\mathrm{TM}}$ Multimode Plate Reader; PerkinElmer, Inc., Boston, MA, USA). All experiments were performed in triplicate.

Cloning of pcDNA4 and mutagenesis. The cDNA of full-length human Mcl-1 was subcloned into the pcDNA4 vector (Invitrogen Life Technologies). Site-directed mutagenesis was performed using a QuikChange lightening kit (Stratagene, La Jolla, CA, USA), according to the manufacturer's instructions. The sequences of the primer sets used for subcloning and mutagenesis are shown in Table I.

Half-life determination. ${ }^{35} \mathrm{~S}$ methionine (Guidechem, Hangzhou, China) pulse-chase labeled glioma cells overexpressing wild-type Mcl-1 (D155G, D155S or L174S) were plated into media deficient in methionine for $1 \mathrm{~h}$ at $37^{\circ} \mathrm{C}$. The cells were washed with PBS and pulsed with labeling media containing ${ }^{35} \mathrm{~S}$ methionine, at a final concentration of $100 \mathrm{mCi} / \mathrm{ml}^{-1}$, and the synthesis of Mcl-1 was inhibited by exposure to ultraviolet light. The cells were washed and harvested at $0,0.5,1$ and $2 \mathrm{~h}$. and treated with $1 \mathrm{mg} / \mathrm{ml}^{-1}$ recombinant TRAIL (R\&D Systems, Minneapolis, MN, USA) for $30 \mathrm{~min}$.

Immunoprecipitation. The cells transfected with wild-type or mutant Mcl-1 were incubated with beads coupled to antibody. Protein A agarose beads (Santa Cruz Biotechnology, Inc., Santa Cruz, CA, USA; $0.5 \mathrm{ml}$ bed volume) were incubated in $1 \mathrm{mg} / \mathrm{ml}$ BSA in $1 \mathrm{ml}$ phosphate-buffered saline containing $100 \mu \mathrm{g}$ polyclonal anti-Mcl-1 antibody (Santa Cruz Biotechnology, Inc.) at $4^{\circ} \mathrm{C}$ overnight. Following incubation, the beads were pelleted by centrifugation and washed three times. The radiolabeled cells were harvested and lysed in cold radioimmunoprecipitation (RIPA) lysis buffer, containing $10 \mathrm{mM}$ Tris- $\mathrm{HCl}$ ( $\mathrm{pH} 7.4$ ), $1 \%$ NP-40, $1 \mathrm{mM}$ EDTA, $0.1 \%$ sodium dodecyl suplhate (SDS) and $150 \mathrm{mM} \mathrm{NaCl}$, 
Table I. Primer sequences for the subcloning and mutagenesis of Mcl-1.

\begin{tabular}{ll}
\hline Primer & \multicolumn{1}{c}{ Sequence $\left(5^{\prime}-3^{\prime}\right)$} \\
\hline $\begin{array}{l}\text { Mcl-1 } \\
\text { Forward }\end{array}$ & CGGGATCCCCCATGTACCCATACGATGTTCCAGATTACGCTTTTGGCCTCAAAAGAAACGCGGTA \\
Reverse & CTATCTTATTAGATATGCCAAACCAGCTCCTAC \\
D155G & CTGGTAATAACACCAGTACGGGCGGGTCACTACCCTCGACGCC \\
Forward & GGCGTCGAGGGTAGTGACCCGCCCGTACTGGTGTTATACCAG \\
Reverse & \\
D155H & CTGGTAATAACACCAGTACGCGCGGGTCACTACCCTCGACGCC \\
Forward & GGCGTCGAGGGTAGTGACCCGCGCGTACTGGTGTTATACCAG \\
Reverse & \\
L174S & CAGAGGAGGAGGAGGACGAGTCGTACCGGCAGTCGCTGGAGAT \\
Forward & ATCTCCAGCGACTGCCGGTACGACTCGTCCTCCTCCTCCTCTG \\
Reverse &
\end{tabular}

Mcl-1, myeloid cell leukemia-1.

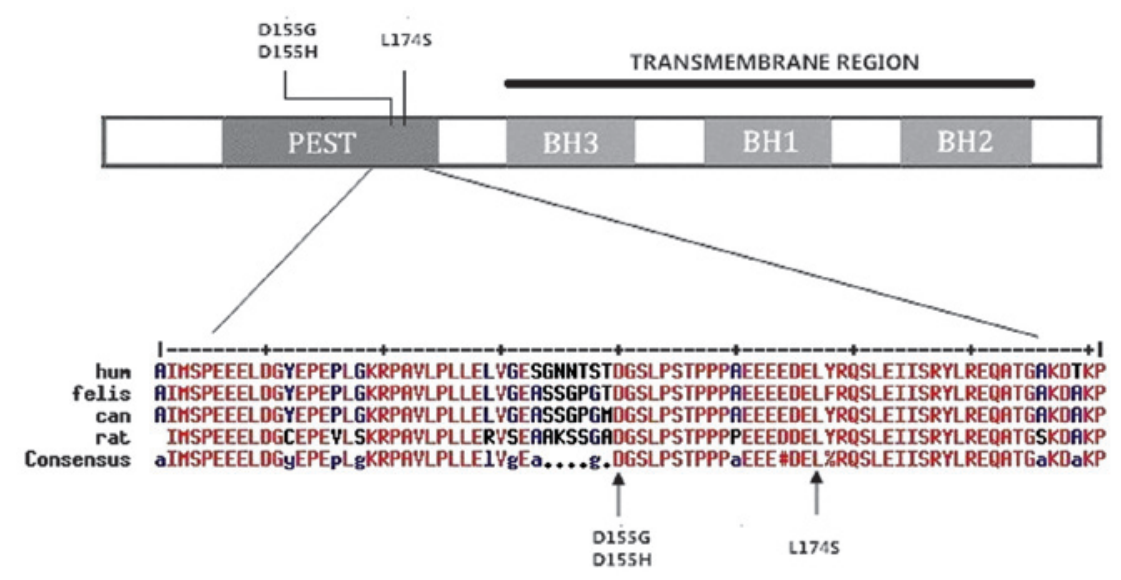

Figure 1. Schematic representation of myeloid cell leukemia-1. The three identified somatic mutations were located in the PEST region of the gene, and the two amino acids involved were highly conserved within different mammalian species.

supplemented with fresh proteinase inhibitor cocktail (Sigma-Aldrich), followed by breaking through a 25 gauge syringe 20 times. Equivalent quantities of the cell extract were adjusted to equal volumes using RIPA buffer, precleared with protein $\mathrm{A}$ agarose beads and clarified by centrifugation at $400 \mathrm{x}$ g for $10 \mathrm{~min}$ at $4^{\circ} \mathrm{C}$. The lysates were subsequently incubated with anti-Mcl-1 antibody at $4^{\circ} \mathrm{C}$ overnight and the immune complexes were precipitated using protein A agarose beads for $6 \mathrm{~h}$ at $120^{\circ} \mathrm{C}$. The immunoprecipitates were washed three times with RIPA buffer and incubated at $95^{\circ} \mathrm{C}$ for $5 \mathrm{~min}$ in SDS sample buffer. The protein samples were separated on an SDS-polyacrylamide gel electrophoresis (PAGE) gel, followed by autoradiography (Biospace Lab, Nesles la Vallée, France) to detect the signals.

Western blot analysis. U251 cells were transfected with wild-type or mutant Mcl-1 and were lysed in lysis buffer (Beyotime, Shanghai, China) on ice $72 \mathrm{~h}$ after transfection. The cell lysates were loaded onto 10\% SDS-PAGE gels (Invitrogen Life Technologies) and the separated proteins were transferred onto a polyvinylidene fluoride membrane (EMD Millipore), which was subsequently blocked with Tris-buffered saline, containing 5\% non-fat dry milk at room temperature for $1 \mathrm{~h}$. The membrane was subsequently incubated with the mouse monoclonal anti-haemagglutinin tag antibody (cat. no. 12ca5; Roche Diagnostics, Mannheim, Germany; 1:1,000) and rabbit polyclonal anti-Mcl-1 antibody (cat. no. sc-819; Santa Cruz Biotechnology, Inc.; 1:2,000) at $4^{\circ} \mathrm{C}$ overnight, followed by incubation with horseradish peroxidase-anti-rabbit secondary antibody (Cell Signaling Technology, Inc., Danvers, MA, USA; cat. no. 7074S) and goat-anti-mouse (cat. no. sc-2031; 1:10,000; Santa Cruz Biotechnology, Inc.) at room temperature for $1.5 \mathrm{~h}$. Chemical fluorescence was detected using an enhanced chemilluminescence kit (Amersham Biosciences, Piscataway, NJ, USA), according to the manufacturer's instructions. The target bands were densitometrically analyzed and normalized against actin.

Statistical analysis. Statistical analysis was performed using SPSS 19.0 software (SPSS, Inc., Chicago, IL, USA). The 
Table II. Description of the somatic mutations identified.

\begin{tabular}{llll}
\hline Gene & \multicolumn{1}{c}{ Nucleotide } & Type & Amino acid change \\
\hline Mcl-1 & GTACGGA $>$ GCGGGTC & Missense & D $>$ D/G $(157 \mathrm{aa})$ \\
Mcl-1 & GTACGG $>$ CACGGGTC & Missense & D $>$ D $/ \mathrm{H}(157 \mathrm{aa})$ \\
Mcl-1 & ACGAGTT $>$ CGTACCG & Missense & L $>\mathrm{S}(174 \mathrm{aa})$ \\
ZMYM3 & GGGTCG $>$ CTCCTG & Missense & $\mathrm{R}>\mathrm{R} / \mathrm{P}(1363 \mathrm{aa})$ \\
SORCS1 & GCCGAG $>$ CGCCCT & Missense & $\mathrm{G}>\mathrm{G} / \mathrm{R}(460 \mathrm{aa})$ \\
ASAP3 & TCAATG $>$ CAGGTC & Missense & $\mathrm{E}>\mathrm{E} / \mathrm{Q}(504 \mathrm{aa})$
\end{tabular}

Mcl-1, myeloid cell leukemia 1; ZMYM3, zinc finger MYM-type protein 3; SORCS1, sortilin-related VPS10 domain containing receptor 1; ASAP3, Arf-GAP with SH3 domain, ANK repeat and PH domain-containing protein 3.

association between somatic mutations and clinicopathologic parameters of GBM was examined using Fisher's exact test. $\mathrm{P}<0.05$ was considered to indicate a statistically significant difference.

\section{Results}

Identification of genetic determinants. To identify the genetic determinants of GBM, the present study initially performed Sanger sequencing of 20 cancer-associated genes in the tumor tissue samples and the corresponding blood genomic DNA from 20 patients with histologically confirmed GBM. Comparison between the tumor and corresponding blood DNA revealed five somatic mutations in the coding regions of four of the 20 candidate genes, with two somatic mutations located in the proline, glutamic acid, serine, threonine-rich (PEST) region of Mcl-1 (Fig. 1). The five somatic mutations were non-synonymous missense point mutations, as shown in Table II. In addition, four of the mutations were heterozygous (three Mcl-1 mutations and one ASAP3 mutation) and the other was homozygous. Notably, within this small set of genetic alterations, multiple somatic mutations were revealed exclusively in Mcl-1, a member of the B-cell lymphoma (Bcl-2) family. Missense variants in Mcl-1 were present in two of the 20 cases (c.A447G and c.T521C), leading to p.D155G and p.L174S substitutions, respectively. The present study then focussed on Mcl-1 and expanded the investigation into the remaining $43 \mathrm{GBM}$ tissue samples. This revealed another somatic mutation (c.G446C, p.D155H), which was in an identical amino acid position as one of the originally identified somatic mutations in Mcl-1.

Sequence comparisons. As shown in Fig. 1, sequence comparisons demonstrated that the affected amino acids in $\mathrm{Mcl}-1$ are highly conserved among species. Projection of the somatic mutations onto the amino acid sequence of Mcl-1 revealed that all three alterations were located in the PEST region of the enzyme. These three missense point mutations may exhibit functional consequences by affecting the degradation of the protein, since they are all accumulated at highly evolutionarily conserved amino acid residues of the respectively affected subunits (Fig. 1). The PEST region is a well known degradation regulatory element in certain proteins (16). The recurrence of mutations affecting these highly conserved

\section{$\mathbf{A}$}

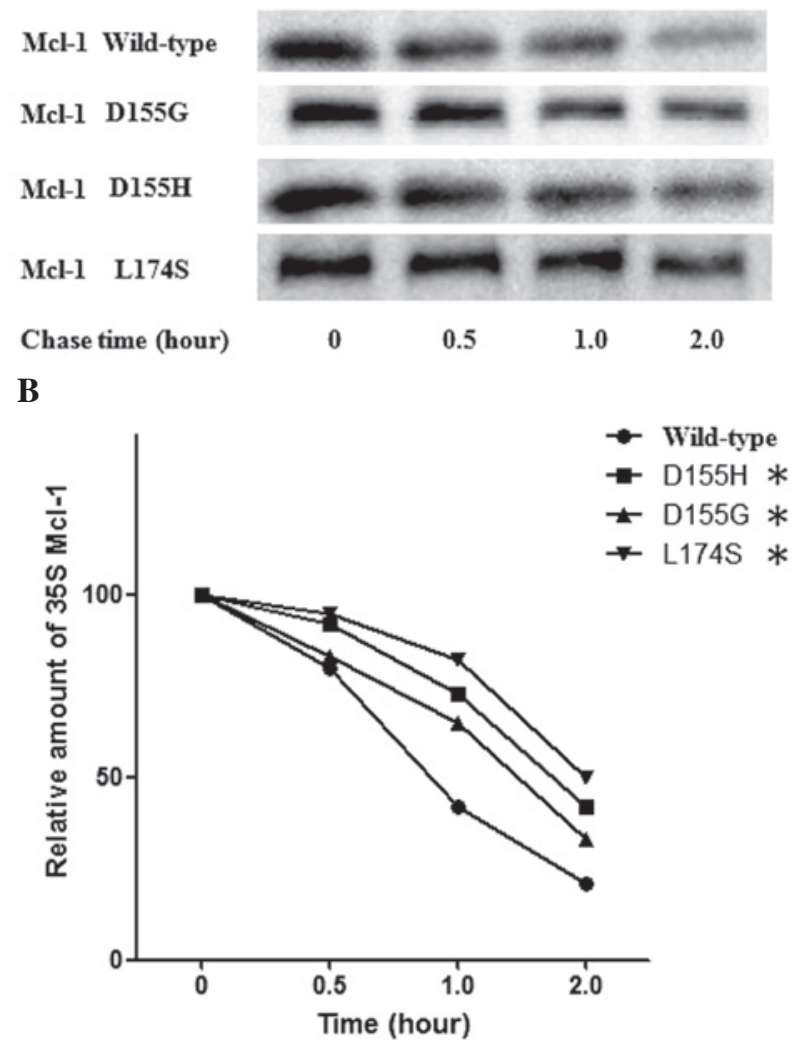

Figure 2. U251 cells transfected with wild-type or mutant Mcl-1 were incubated in methionine starvation medium for $1 \mathrm{~h}$ prior to the addition of ${ }^{35} \mathrm{~S}$ methionine and pulsing for $1 \mathrm{~h}$. The cells were subsequently treated with ultraviolet radiation to inhibit the synthesis of Mcl-1 and chased in complete medium for 0, 0.5, 1 or $2 \mathrm{~h}$. Mcl-1 was immunoprecipitated and half-life was determined. (A) Protein half-life was evaluated according to the density of the protein bands. (B) Summary of the half-lives of the wild-type and mutant Mcl-1 proteins. The half-lives of the mutant Mcl-1 proteins were significantly lower, as compared with the wild-type ( $\mathrm{P}<0.05$, compared with the wild-type). Mcl-1, myeloid cell leukemia-1.

regions involved in the regulation of degradation is suggestive of a gain-of-function effect. Therefore, these mutations are hypothesized to compromise the degradation of the protein, resulting in the intracellular accumulation of Mcl-1.

Mcl-1 post-translational modifications. Mcl-1 is reported to undergo various post-translational modifications and the present study hypothesized that the amino acid alternations identified 
A

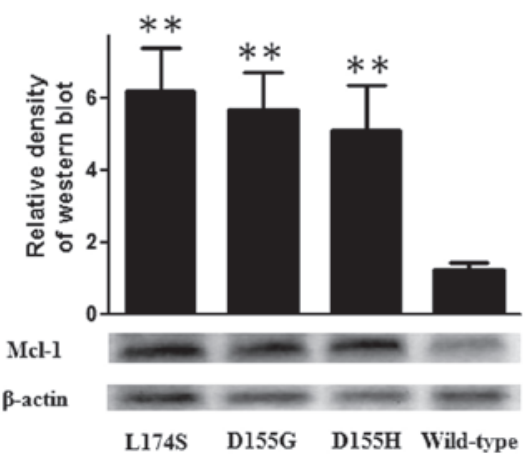

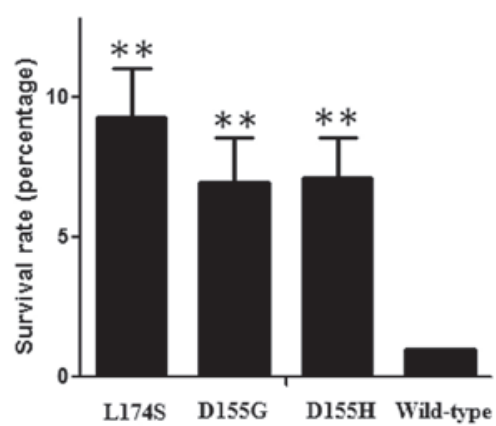

Figure 3. (A) Expression levels of wild-type and mutant Mcl-1 in the U251 cells was determined by western blotting $48 \mathrm{~h}$ after transfection, and the relative density of the target bands were quantified. (B) Comparison of the survival rates of U251 cells $48 \mathrm{~h}$ after transfection with wild-type or mutant Mcl-1. "P $<0.05$, ${ }^{* *} \mathrm{P}<0.01$, compared with wild-type. Mcl-1, myeloid cell leukemia-1.

A

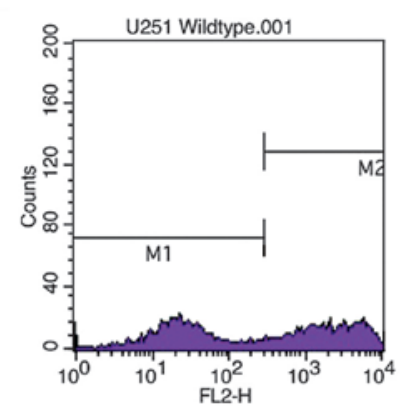

C

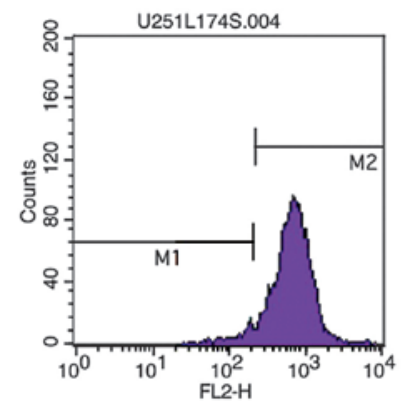

B

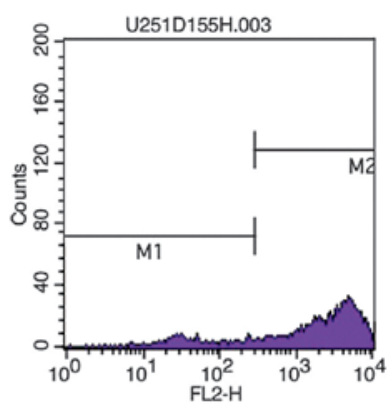

D

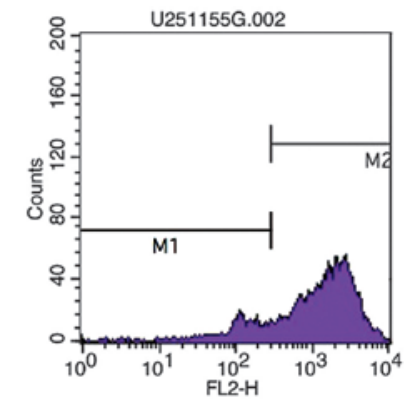

E

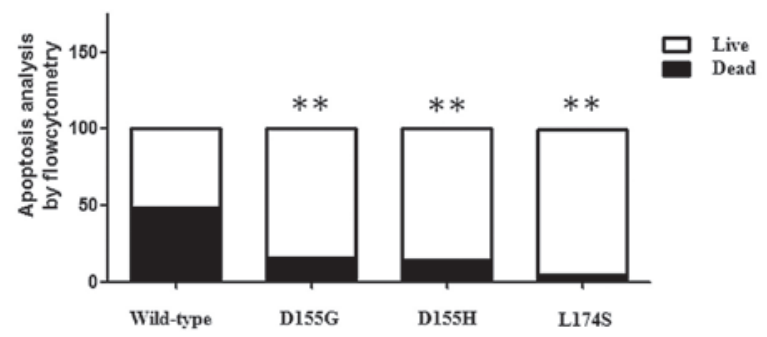

Figure 4. Apoptotic index of cells transfected with (A) wild-type, and mutant Mcl-1: (B) D115G; (C) D155H; and (D) D155H. M1, live cells; M2, apoptotic cells. (E) Summary of the apoptotic status of the cells transfected with wild-type and mutant Mcl-1. " $\mathrm{P}<0.05$, ${ }^{* *} \mathrm{P}<0.01$, compared with wild-type. Mcl-1, myeloid cell leukemia-1.

may affect the phosphorylation of the residual amino acids, thereby preventing the degradation of the protein. However, no differences in the phosphorylation of Mcl-1 were identified between the wild-type and the mutants (data not shown). The half-life of the Mcl-1 protein was previously reported to be between 30 and 90 min (16-18). The present study subsequently determined whether the mutations identified affected the half-life of Mcl-1. The wild-type Mcl-1 or the mutant forms were expressed in the GBM cell line and the half-life of Mcl-1 was determined using ${ }^{35} \mathrm{~S}$ methionine pulse-chase labeling. Consistent with the previous findings, the wild-type Mcl-1 had a half-life of $\sim 1 \mathrm{~h}$ in the U251 cells (Fig. 2). By contrast, the three mutants were more stable compared with the wild-type and exhibited a half-life of $\sim 2 \mathrm{~h}$ (Fig. 2).

Cell proliferation. Since Mcl-1 functions as an anti-apoptotic protein and the somatic mutations resulted in the intracellular accumulation of the enzyme, the present study expressed the 
mutants and wild-type Mcl-1 transiently in U251 cells and examined the cell proliferation rate using an MTT assay. As shown in Fig. 3, the ectopic expression levels of the three mutants were significantly higher compared with the wild-type, and the survival rate of the U251 cells transfected with wild-type Mcl-1 was significantly higher compared with the mutants treated with TRAIL. To investigate the underlying mechanism, the present study examined whether mutant Mcl-1 had a more marked effect on TRAIL-induced apoptosis in glioma cells using flow cytometry. The Mcl-1 mutants suppressed TRAIL-induced apoptosis to a greater extent compared with the wild-type in the glioma cell line (Fig. 4)

\section{Discussion}

The identification of cancer specific somatic mutations may improve current understanding of the molecular mechanisms underlying tumorigenesis and the progression of malignancy in human cells. This has substantially contributed to the development of highly targeted treatments using monoclonal antibodies or specific inhibitors, which are characterized by a marked improvement in clinical efficacy and an evident reduction in adverse effects compared with conventional chemotherapeutic agents $(19,20)$. Positive results from several clinical trials have led to the approval of similar therapeutic agents for melanoma (vemurafenib/BRAF), non-small cell lung cancer (crizotinib/anaplastic lymphoma kinase) and myelodysplasia (ruxolitininb/Janus kinase 2; JNK2) (18), and the improved capability to identify novel targets is likely to assist in expanding the list of targeted therapies. GBM is one of the most life-threatening malignancies and is the most common type of primary brain tumor in adults (21). The standard treatments, including surgery or chemoradiotherapy, are rarely curative, and the majority of tumors recur within a few months. A previous comprehensive genomic study demonstrated that the genetic landscape of GBM is heterogeneous, with $80 \%$ of patients affected in one of the three main signaling pathways: p53, phosphatidylinositol-4,5-bisphosphate 3-kinase $\alpha$ and retinoblastoma (6). The present study identified a number of protein-altering somatic mutations by directly sequencing 20 cancer-associated genes (Table II). Notably, within this small set of genetic alterations, multiple somatic mutations were identified exclusively in Mcl-1. Missense variants in Mcl-1 were present in two of the 20 cases (D155G and L174S). Investigating Mcl-1 in the remaining 43 GBM cases, revealed another somatic mutation (D155H), which was close to the former two variants.

Mcl-1, initially identified in differentiating myeloid cells, is a member of the anti-apoptotic Bcl-2 family with unique structural features (22). Although the C-terminal sequence of Mcl-1 shares similarities with other Bcl-2 family members, the $\mathrm{N}$-terminus lacks the characteristic BH4 domain. Instead, it contains two highly conserved proline, glutamic acid, serine and threonine-rich PEST sequences (23), with two caspase cleavage sites, Asp127 and Asp157, and several phosphorylation sites, which are involved in regulating the degradation and stability of Mcl-1 (24-27). Thr163 is the major phosphorylation site in Mcl-1, and extracellular signal-regulated kinase-mediated phosphorylation at Thr163 and Thr92 increases its binding to Pin-1, thereby increasing its stability and its antiapoptotic function (28). By contrast, phosphorylation of Ser121 and Thr163 suppresses the anti-apoptotic function of Mcl-1 (29,30) and joint phosphorylation of Thr163 and Ser159, mediated by JNK and glycogen synthase kinase $3 \beta$, promotes the degradation of Mcl-1 and interferes with its interaction with the pro-apoptotic protein, Bim (31).

The present study demonstrated that the affected amino acids are highly conserved among species (Fig. 1). Projection of the somatic mutations onto the amino acid sequence of Mcl-1 revealed that the three alterations were located in the PEST region of the enzyme. The recurrence of mutations affecting these highly conserved regions, which are involved in the regulation of degradation, is suggestive of a gain-of-function effect. To investigate the effect of these somatic mutations on the function of Mcl-1, the coding sequences of wild-type Mcl-1 and the mutants corresponding to the amino acid alternations were cloned into pcDNA4. These constructs were subsequently expressed in the GBM cell line and the half-life of Mcl-1 was determined by ${ }^{35} \mathrm{~S}$ methionine pulse-chase labeling. Wild-type Mcl-1 exhibited a half-life of $\sim 1 \mathrm{~h}$ in the U251 cells (Fig. 2). By contrast, the mutants were more stable, with a half-life of $\sim 2$ h (Fig. 2).

Mcl-1 is readily induced by various survival regulators, including epidermal growth factor, vascular endothelial growth factor, granulocyte-macrophage colony-stimulating factor, mitogen activated protein kinase and JAK/signal transducer and activator of transcription signaling cascades, and is also rapidly degraded by certain apoptosis-inducing signals $(32,33)$. The rapid induction and degradation of Mcl-1 suggested that Mcl-1 functions as sensor and reactor of environmental stimuli to maintain a balance between cell survival and death, suggesting that Mcl-1 is an essential regulator of proliferation or differentiation of human cells $(34,35)$. Inhibition or elimination of Mcl-1 in response to cytotoxic signals is considered critical in cell death in a number of normal and malignant cells $(34,36)$. In addition, increased expression of Mcl-1 may not only promote short-term survival in a wide range of cells, but may also cause long-term immortalization and the malignant transformation of certain human cells (37-39). Previous studies have suggested that overexpression of Mcl-1 may be involved in the mechanism underlying chemoresistance in a number of human malignancies, including breast cancer, leukemia, melanoma, pancreatic cancer and hepatocellular carcinoma $(33,40)$. The present study examined the effect of the identified mutants on the growth of glioma cells and TRAIL-induced apoptosis in U271 cells, and found that the survival rate of the cells transfected with wild-type Mcl-1 was significantly lower compared with the Mcl-1 mutants. Additionally, the Mcl-1 mutants suppressed TRAIL-induced apoptosis to a greater extent compared with the wild-type in the glioma cell lines (Figs. 3 and 4).

In conclusion, despite the small sample size, the present study identified a panel of somatic mutations in 20 cancer-associated genes, and found that several mutations may be pathogenic with potential detrimental impacts on gliomagenesis, within which multiple somatic mutations were identified in Mcl-1. The preliminary functional investigations suggested that the mutations increased the stability of Mcl-1 and contributed to the pathogenesis of GBM. Future studies using a larger number of patients from different ethnic backgrounds are required to confirm the findings of the present study. 


\section{References}

1. Louis DN, Ohgaki H, Wiestler OD, Cavenee WK, Burger PC, Jouvet A, Scheithauer BW and Kleihues P: The 2007 WHO classification of tumours of the central nervous system. Acta Neuropathol 114: 97-109, 2007

2. Stupp R, Mason WP, van den Bent MJ, Weller M, Fisher B, et al: Radiotherapy plus concomitant and adjuvant temozolomide for glioblastoma. N Engl J Med 352: 987-996, 2005.

3. Hemminki K and Li X: Familial risks in nervous system tumors. Cancer Epidemiol Biomarkers Prev 12: 1137-1142, 2003.

4. Scheurer ME, Etzel CJ, Liu M, El-Zein R, Airewele GE, Malmer B, Aldape KD, Weinberg JS, Yung WK and Bondy Ml Aggregation of cancer in first-degree relatives of patients with glioma. Cancer Epidemiol Biomarkers Prev 16: 2491-2495, 2007.

5. Cancer Genome Atlas Research Network: Comprehensive genomic characterization defines human glioblastoma genes and core pathways. Nature 455: 1061-1068, 2008.

6. Parsons DW, Jones S, Zhang X, Lin JC, Leary RJ, et al: An integrated genomic analysis of human glioblastoma multiforme. Science 321: 1807-1812, 2008.

7. Vogelstein B and Kinzler KW: Cancer genes and the pathways they control. Nat Med 10: 789-799, 2004.

8. Greenman C, Stephens P, Smith R, Dalgliesh GL, Hunter C, Bignell G, Davies H, Teague J, Butler A, Stevens C, et al: Patterns of somatic mutation in human cancer genomes. Nature 446: $153-158,2007$

9. Jones S, Zhang X, Parsons DW, Lin JC, Leary RJ, Angenendt P, Mankoo P, Carter H, Kamiyama H, Jimeno A, et al: Core signaling pathways in human pancreatic cancers revealed by global genomic analyses. Science 321: 1801-1806, 2008.

10. Sjöblom T, Jones S, Wood LD, Parsons DW, Lin J, Barber TD, Mandelker D, Leary RJ, Ptak J, Silliman N, et al: The consensus coding sequences of human breast and colorectal cancers. Science 314: 268-274, 2006.

11. Wood LD, Parsons DW, Jones S, Lin J, Sjoblom T, Leary RJ, Shen D, Boca SM, Barber T, Ptak J, et al: The genomic landscapes of human breast and colorectal cancers. Science 318: 1108-1113, 2007

12. Lichtenstein P, Holm NV, Verkasalo PK, Iliadou A, Kaprio J, Koskenvuo M, Pukkala E, Skytthe A, Hemminki K Environmental and heritable factors in the causation of cancer-analyses of cohorts of twins from Sweden, Denmark and Finland. N Engl J Med 343: 78-85, 2000

13. Bentivegna S, Zheng J, Namsaraev E, Carlton VE, Pavlicek A, Moorhead M, Siddiqui F, Wang Z, Lee L, Ireland JS, et al: Rapid identification of somatic mutations in colorectal and breast cancer tissues using mismatch repair detection (MRD). Hum Mutat 29: 441-450, 2008.

14. Di Lonardo A, Nasi S and Pulciani S: Cancer: we should not forget the past. J Cancer 6: 29-39, 2015.

15. Erstad DJ and Jr JC: Mutational analysis of merkel cell carcinoma. Cancers (Basel) 6: 2116-2136, 2014.

16. Schubert KM and Duronio V: Distinct roles for extracellular-signal-regulated protein kinase (ERK) mitogen-activated protein kinases and phosphatidylinositol 3 -kinase in the regulation of Mcl-1 synthesis. Biochem J 356 473-480, 2001

17. Chao JR, Wang JM, Lee SF, Peng HW, Lin YH, Chou CH, et al: $\mathrm{Mcl}-1$ is an immediate-early gene activated by the granulocyte-macrophage colony-stimulating factor (GMCSF) signaling pathway and is one component of the GM-CSF viability response. Mol Cell Biol 18: 4883-4898, 1998

18. Nijhawan D, Fang M, Traer E, Zhong Q, Gao W, Du F and Wang X. Elimination of Mcl-1 is required for the initiation of apoptosis following ultraviolet irradiation. Genes Dev 17 1475-1486, 2003.

19. Varela I, Tarpey P, Raine K, Huang D, Ong CK, et al: Exome sequencing identifies frequent mutation of the SWI/SNF complex gene PBRM1 in renal carcinoma. Nature 469: 539-542, 2011.

20. Jones S, Wang TL, Shih IM, Mao TL, Nakayama K, et al: Frequent mutations of chromatin remodeling gene ARID1A in ovarian clear cell carcinoma. Science 330: 228-231, 2010.
21. Wen PY and Kesari S. Malignant Gliomas in Adults. N Engl J Medicine 359: 492-507, 2008.

22. Kozopas KM, Yang T, Buchan HL, Zhou P and Craig RW: MCL1, a gene expressed in programmed myeloid cell differentiation, has sequence similarity to Bcl-2. Proc Natl Acad Sci USA 90: 3516-3520, 1993.

23. Day CL, Chen L, Richardson SJ, Harrison PJ, Huang DCS and Hinds MG: Solution structure of prosurvival Mcl-1 and characterization of its binding by proapoptotic $\mathrm{BH} 3$-only ligands. J Bio Chem 280: 4738-4744, 2005

24. Clohessy JG, Zhuang J and Brady HJM, Characterisation of Mcl-1 cleavage during apoptosis of haematopoietic cells Br J Haemato 125: 655-665, 2004.

25. Domina AM, Smith JH and Craig RW: Myeloid cell leukemia 1 is phosphorylated through two distinct pathways, one associated with extracellular signal regulated kinase activation and the other with $\mathrm{G} 2 / \mathrm{M}$ accumulation or protein phosphatase $1 / 2 \mathrm{~A}$ inhibition. J Biol Chem 275: 21688-21694, 2000.

26. Domina AM, Vrana JA, Gregory MA, Hann SR and Craig RW, MCL1 is phosphorylated in the PEST region and stabilized upon ERK activation in viable cells and at additional sites with cytotoxic okadaic acid or taxol. Oncogene 23: 5301-5315, 2004.

27. Zhong Q, Gao W, Du F and Wang X: Mule/ARFBP1, a BH3-only E3 ubiquitin ligase, catalyzes the polyubiquitination of Mcl-1 and regulates apoptosis. Cell 121: 1085-1095, 2005.

28. Ding Q, Huo L, Yang JY, Xia W, Wei Y, Liao Y, Chang CJ, Yang Y, Lai CC, Lee DF, Yen CJ, Chen YJR, Hsu JM, Kuo HP, Lin CY, Tsai FJ, Li LY, Tsai CH and Hung MC: Down-regulation of myeloid cell leukemia-1 through inhibiting Erk/Pin 1 pathway by sorafenib facilitates chemosensitization in breast cancer Cancer Res 68: 6109-6117, 2008.

29. Inoshita S, Takeda K, Hatai T, Terada Y, Sano M, Hata J, Umezawa A and Ichijo $\mathrm{H}$ : Phosphorylation and inactivation of myeloid cell leukemia 1 by JNK in response to oxidative stress, J Biol Chem 277: 43730-43734, 2002.

30. Morel C, Carlson SM, White FM and Davis RJ: Mcl-1 integrates the opposing actions of signaling pathways that mediate survival and apoptosis. Mol Cell Biol 29: 3845-3852, 2009.

31. Maurer U, Charvet C, Wagman AS, Dejardin E and Green DR: Glycogen synthase kinase-3 regulates mitochondrial outer membrane permeabilization and apoptosis by destabilization of Mcl-1. Mol Cell 21: 749-760, 2006.

32. Michels J, Johnson PW and Packham G. Mcl-1. Int J Biochem Cell Biol 37: 267-71, 2005.

33. Craig RW. Mcl-1 provides a window on the role of the Bcl-2 family in cell proliferation, differentiation and tumorigenesis. Leukemia 16: 444-454, 2002.

34. Rinkenberger JL, Horning S, Klocke B, Roth K and Korsmeyer SJ. Mcl-1 deficiency results in periimplantation embryonic lethality. Genes Dev 14: 23-27, 2000

35. Opferman JT, Letai A, Beard C, Sorcinelli MD, Ong CC and Korsmeyer SJ. Development and maintenance of B and $\mathrm{T}$ lymphocytes requires antiapoptotic Mcl-1. Nature 426: 671-676, 2003

36. Willis SN, Chen L, Dewson G, Wei A, Naik E, Fletcher JI, et al: Proapoptotic Bak is sequestered by Mcl-1 and Bcl-xL, but not Bcl-2, until displaced by BH3-only proteins. Genes Dev 19: $1294-1305,2005$

37. McDonnell TJ and Korsmeyer SJ. Progression from lymphoid hyperplasia to high-grade malignant lymphoma in mice transgenic for the $\mathrm{t}(14 ; 18)$. Nature 349: 254-256, 1991.

38. Zhou P, Levy NB, Xie H, et al: Mcl-1 transgenic mice exhibit a high incidence of B-cell lymphoma manifested as a spectrum of histologic subtypes. Blood 97: 3902-3909, 2001.

39. Townsend KJ,Zhou P, Qian L, et al: Regulation of Mcl-1 through a serum response factor/Elk-1-mediated mechanism links expression of a viability-promoting member of the Bcl-2 family to the induction of hematopoietic cell differentiation. J Biol Chem 274: 1801-1813, 1999.

40. Thallinger C, Wolschek MF, Maierhofer H, et al: Mcl-1 is a novel therapeutic target for human sarcoma: synergistic inhibition of human sarcoma xenotransplants by a combination of mcl-1 antisense oligonucleotides with low-dose cyclophosphamide. Clin Cancer Res 10: 4185-4191, 2004. 